CLINICAL STUDY

\title{
Resistance to leptin-replacement therapy in Berardinelli-Seip congenital lipodystrophy: an immunological origin
}

\author{
Jacques Beltrand $^{1,2}$, Najiba Lahlou ${ }^{3}$, Tifenn Le Charpentier ${ }^{2,4}$, Guy Sebag ${ }^{2,4,5}$, Sofia Leka ${ }^{1,2}$, \\ Michel Polak ${ }^{6,7}$, Nadia Tubiana-Rufi ${ }^{8}$, Didier Lacombe ${ }^{9}$, Marc de Kerdanet ${ }^{10}$, Frederic Huet $^{11}$, \\ Jean-Jacques Robert ${ }^{6,7}$, Didier Chevenne ${ }^{11}$, Pierre Gressens ${ }^{2,4}$ and Claire Lévy-Marchal ${ }^{1,2}$ \\ ${ }^{1}$ Unité INSERM U690, Hôpital Robert Debré, 48 Boulevard Sérurier, FR-75019 Paris, France, ${ }^{2}$ Paris 7 University, Paris FR-75215 Cedex 13 , France, \\ ${ }^{3}$ Paediatric Hormonology and Metabolic Diseases, Saint-Vincent de Paul Hospital, Paris FR-75004, France, ${ }^{4}$ INSERM, U676, Paris FR-75019, France, \\ ${ }^{5}$ Paediatric Radiology, Robert Debré Hospital, Paris FR-75019, France, ${ }^{6}$ Paediatric Endocrinology, Diabetology and Gynaecology, Necker-Enfants Malades \\ Hospital, Paris FR-75015, France, ${ }^{7}$ Paris 5 University, Paris FR-75270 Cedex 06, France, ${ }^{8}$ Paediatric Endocrinology, Robert Debré Hospital, \\ Paris FR-75019, France, ${ }^{9}$ Genetic Unit, Pellegrin Hospital, Bordeaux FR-33000, France, ${ }^{10}$ Paediatric Unit, South Hospital, Rennes FR-32503, \\ France, ${ }^{11}$ Paediatric Unit 1, Children Hospital, Dijon FR-21000, France and ${ }^{12}$ Biochemistry and Hormonology Unit, Robert Debré Hospital, \\ Paris FR-75019, France
}

(Correspondence should be addressed to J Beltrand at Unité INSERM U690, Hôpital Robert Debré; Email: beltrand@me.com)

\begin{abstract}
Context: Recently, in a 4-month proof-of-concept trial, beneficial metabolic effects were reported in non-diabetic children with Berardinelli-Seip congenital lipodystrophy (BSCL); this information prompted us to hypothesize that long-term leptin-replacement therapy might improve or reverse the early complications of the disease in these patients.

Patients and methods: A 28-month trial was implemented in eight patients. Efficacy assessment was based on a decrease in serum triglyceride concentrations, and/or a decrease in liver volume and/or an increase in insulin sensitivity of at least $30 \%$ respectively. The response was defined as follows: total (3/3 positive criteria), partial ( 1 or $2 / 3)$, or negative (0/3). Anti-leptin antibodies were measured with a radiobinding assay, and a neutralizing effect was assessed in primary cultures of embryonic neurons incubated with an apoptotic agent ( $N$-methyl-D-aspartate) and the patient serum, with or without leptin.

Results: A negative or partial response to treatment was observed in five of eight patients even when leptin dosages were increased. A displaceable leptin binding was detectable in all patients after 2 months of treatment. At 28 months, binding was higher in the patients with a negative response than in the total responders, and it paralleled both the increase in leptin dosage and serum leptin concentrations. Co-incubation of embryonic neurons with serum from two patients with a negative response inhibited the neuroprotective effect of leptin.

Conclusion: Under leptin therapy, patients with BSCL may develop a resistance to leptin, which could be partly of immunological origin, blunting the previously reported beneficial effects.
\end{abstract}

European Journal of Endocrinology 162 1083-1091

\section{Introduction}

Berardinelli-Seip congenital lipodystrophy (BSCL) is a rare but very severe congenital syndrome characterized by the lack of adipose tissue $(1,2)$. It is a genetically heterogeneous disorder with an autosomal recessive inheritance for which three genes encoding proteins expressed in the adipocyte, and playing a role in lipid metabolism, have been identified (3-6). Patients with BSCL have high circulating concentrations of triglycerides and develop ectopic fat depots leading to severe complications early in life. Hepatic storage promotes steatosis and fibrosis and later cirrhosis. Insulin resistance is observed very early in life in these patients, progressing ineluctably toward diabetes which appears around or even before puberty (7). Additionally, dyslipidemia favors arteriosclerosis and cardiovascular diseases, and can affect other organs such as the pancreas where hypertriglyceridemia can cause acute pancreatitis. The prognosis of the disease is very poor, and patients often die in the third decade of life. Treatment is not standardized, is only based on symptoms or complications presented by the patients, and is only able to delay the progression of the disease.

As a direct consequence of the lack of adipose tissue, these patients show nearly undetectable circulating concentrations of leptin, an adipokine which plays a key role in energy regulation through both central and peripheral mechanisms $(8-12)$. The production of recombinant human leptin has provided the opportunity to determine whether leptin-replacement therapy would improve the extremely severe metabolic 
derangement found in these patients $(13,14)$. Following two trials in adults, we have reported previously that leptin was able to reduce or even correct insulin resistance, dyslipidemia, and hepatomegaly in five of seven patients after 4 months of therapy (15). However, full reversal cannot be attained in all patients in such a short period of time since up to 1 year of treatment has been reported as being necessary for the improvement of hormonal, metabolic, and immune disorders in some adults with lipodystrophy (13). Moreover, if the benefits of leptin replacement can be sustained on a long-term basis, this treatment would represent the first opportunity to reduce the progression of the severe metabolic complications by blocking ectopic fat storage in children with BSCL. However, long-term data $(>1$ year) are only available in a few reports $(13,14)$. The aim of this second trial in children with BSCL was to assess the long-term efficacy and safety of leptin-replacement therapy to correct for the metabolic disorders.

\section{Research design and methods}

\section{Patients}

Eight patients (two girls and six boys, Tanner stage between I and IV) were enrolled in the study. Inclusion criteria were genetically assessed diagnosis of BSCL, low leptin concentrations $(<3 \mathrm{ng} / \mathrm{ml})$, and at least one abnormal feature (hyperinsulinemia $>15 \mathrm{mUI} / \mathrm{l}$ and/or triglyceride concentration $>2 \mathrm{mmol} / \mathrm{l}$ ). Characteristics at enrollment are given in Table 1. Seven patients (patients 1-7) were previously enrolled in the first 4-month trial (15), and the time between the two studies was $\sim 18$ months.

\section{Study design}

The study was a prospective, open-labeled, nonrandomized phase II trial. Children were kept on their recommended diets for the duration of the trial (low-lipid diet: $20 \%$ of daily caloric intake, mediumchain fatty acid supplementation). Informed written consent was obtained from all subjects and from their families. The Paris/St-Louis ethics committee approved the protocol. Criteria for a positive response to treatment were defined as a reduction in liver volume of at least $30 \%$ and/or a $30 \%$ improvement in insulin sensitivity and/or a $30 \%$ of fasting triglycerides. These criteria were similar to those of the first trial and were the ones used in the NHI trial. Patients showing improvement in the three criteria were considered as total responders, and those with improvement in one or two criteria were considered as partial responders and lack of improvement in any of the criteria was defined as a negative response.

\section{Leptin administration}

Recombinant methionyl human leptin was provided by Amylin Inc. (San Diego, CA, USA). Leptin was administered subcutaneously once a day. The dosage was progressively increased over the first 2 months to achieve a dosage of $0.06 \mathrm{mg} / \mathrm{kg}$ per day, which was maintained throughout the first year. At the end of the first year, the dosage was increased to 0.09 or $0.12 \mathrm{mg} / \mathrm{kg}$ per day in the children who showed either a partial or no response respectively. At the time of evaluation, the total duration of leptin-replacement therapy was 28 months in all patients, and the dosage was $0.06 \mathrm{mg} / \mathrm{kg}$ per day in one patient, $0.09 \mathrm{mg} / \mathrm{kg}$ per day in four patients, and $0.12 \mathrm{mg} / \mathrm{kg}$ per day in three patients (Table 2).

\section{Procedures}

Blood lipids, insulin sensitivity, energy expenditure, and liver enzymes were measured every 4 months during a 48-h hospitalization in the Clinical Investigation Unit at Robert Debré Hospital in Paris. Body composition and liver volume were measured at enrollment, month 12 and month 28. Blood lipids were measured on a single sample before the clamp and following an overnight fasting preceded by a standardized dinner.

Body fat and whole body bone mineral density were determined by dual-energy X-ray absorptiometry (DEXA, Lunar Prodigy DXP Pro, GE Medical Systems, Madison, WI, USA). Liver volume was calculated using computed tomography (CT) scanning applying a standardized procedure with measurements of height, width, and length (accurate to $0.1 \mathrm{~cm}$ ). Respiratory quotient and resting energy expenditure were determined by indirect calorimetry using a QUARK PFT (Cosmed, Roma, Italy), which was performed before the euglycemic-hyperinsulinemic clamp after an overnight fast. Children were kept in bed and remained quiet while watching television. Respiratory gas exchange was continuously monitored for $10 \mathrm{~min}$ using a ventilated hood. The measurements obtained between the first and the fifth minute were discarded to allow the children to get accustomed to the procedure. Energy expenditure was calculated using the equations of Livesey et al. (16).

Insulin sensitivity was measured as the peripheral glucose uptake (M) at steady state of a 120-min euglycemic-hyperinsulinemic clamp (17). Insulin was infused throughout the test at $40 \mathrm{mUI} / \mathrm{m}^{2}$ per $\mathrm{min}$. Peripheral glucose uptake was calculated as the average glucose infusion rate (plus hepatic glucose output (HGO)) at a steady state over two consecutive 20-min periods, and was corrected for mean plasma glucose concentrations and fat-free mass. Glucose turnover rate was determined by the tracer dilution method utilizing $\left[{ }^{2} \mathrm{H}\right]$-glucose. HGO was calculated at baseline and at the steady state of the euglycemic clamp. In one young 


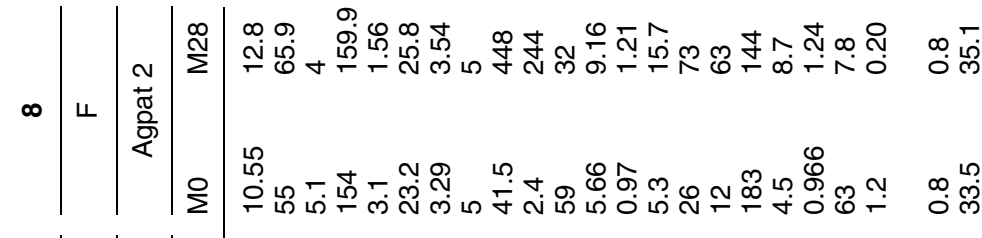

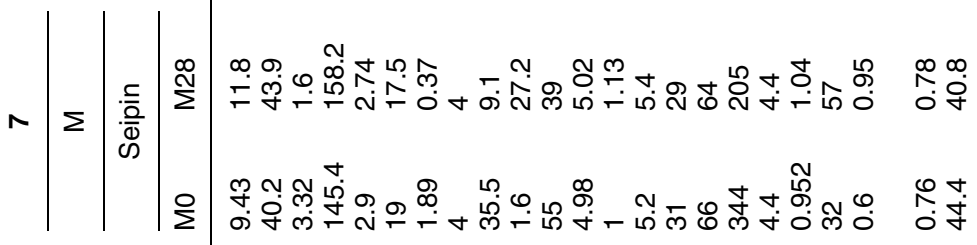

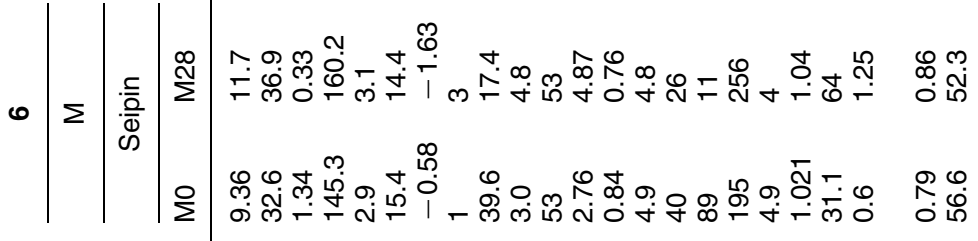

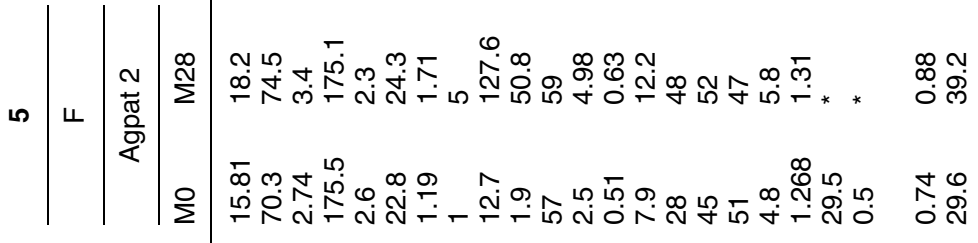

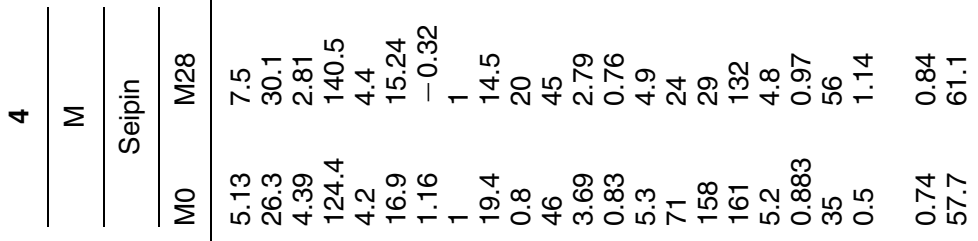

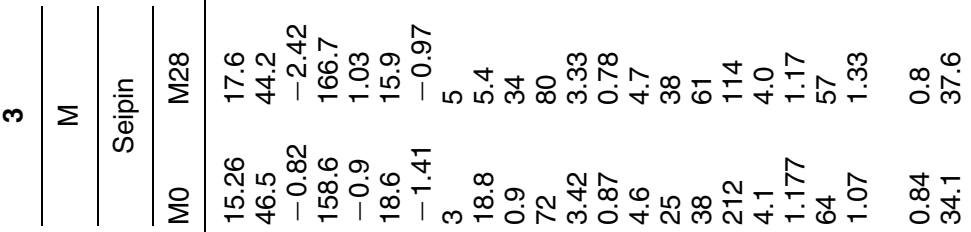

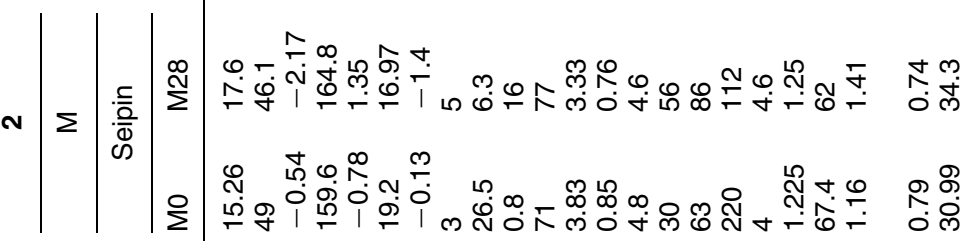

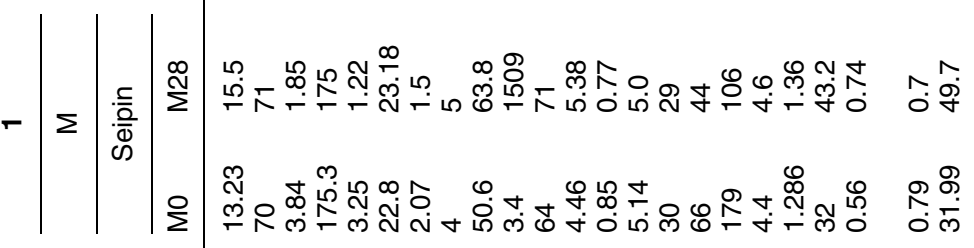

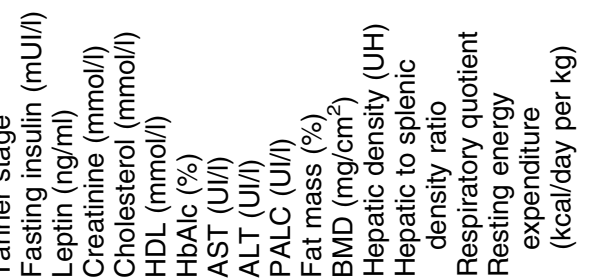


Table 2 Response to leptin-replacement treatment at months 4, 12, and 28.

\begin{tabular}{|c|c|c|c|c|}
\hline Patient & & M4 & M12 & M28 \\
\hline \multirow[t]{5}{*}{1} & Leptin dose (mg/kg per day) & 0.06 & 0.06 & 0.12 \\
\hline & Insulin sensitivity & - & - & - \\
\hline & Triglycerides & - & - & - \\
\hline & Hepatic volume & - & - & - \\
\hline & Response & Negative & Negative & Negative \\
\hline \multirow[t]{5}{*}{2} & Leptin dose (mg/kg per day) & 0.06 & 0.06 & 0.06 \\
\hline & Insulin sensitivity & + & + & + \\
\hline & Triglycerides & + & + & + \\
\hline & Hepatic volume & - & + & + \\
\hline & Response & Partial & Total & Total \\
\hline \multirow[t]{5}{*}{3} & Leptin dose (mg/kg per day) & 0.06 & 0.06 & 0.09 \\
\hline & Insulin sensitivity & - & + & + \\
\hline & Triglycerides & + & + & + \\
\hline & Hepatic volume & - & + & + \\
\hline & Response & Partial & Total & Total \\
\hline \multirow[t]{5}{*}{4} & Leptin dose (mg/kg per day) & 0.06 & 0.06 & 0.09 \\
\hline & Insulin sensitivity & - & - & - \\
\hline & Triglycerides & - & + & + \\
\hline & Hepatic volume & - & - & + \\
\hline & Response & Negative & Partial & Partial \\
\hline \multirow[t]{5}{*}{5} & Leptin dose (mg/kg per day) & 0.06 & 0.06 & 0.12 \\
\hline & Insulin sensitivity & - & - & - \\
\hline & Triglycerides & - & - & - \\
\hline & Hepatic volume & - & - & - \\
\hline & Response & Negative & Negative & Negative \\
\hline \multirow[t]{5}{*}{6} & Leptin dose (mg/kg per day) & 0.06 & 0.06 & 0.09 \\
\hline & Insulin sensitivity & - & - & + \\
\hline & Triglycerides & + & - & - \\
\hline & Hepatic volume & - & + & + \\
\hline & Response & Partial & Partial & Partial \\
\hline \multirow[t]{5}{*}{7} & Leptin dose (mg/kg per day) & 0.06 & 0.06 & 0.09 \\
\hline & Insulin sensitivity & + & + & + \\
\hline & Triglycerides & + & + & + \\
\hline & Hepatic volume & - & + & + \\
\hline & Response & Partial & Total & Total \\
\hline \multirow[t]{5}{*}{8} & Leptin dose (mg/kg per day) & 0.06 & 0.06 & 0.12 \\
\hline & Insulin sensitivity & - & - & - \\
\hline & Triglycerides & - & - & - \\
\hline & Hepatic volume & - & - & - \\
\hline & Response & Negative & Negative & Negative \\
\hline
\end{tabular}

Hepatic volume: $+=$ reduction in liver volume $\geq 30 \%$ between month 0 and month $M$, insulin sensitivity: $+=\geq 30 \%$ increase in insulin sensitivity between month 0 and month $\mathrm{M}$, triglycerides $\geq 30 \%$ reduction of fasting triglycerides between month and month $\mathrm{M}$.

patient (patient 4), insulin sensitivity was assessed by calculating parameters derived from the glucose tolerance test. Quantitative insulin sensitivity check index (QUICKI) was calculated as follows: QUICKI $=1$ / (log fasting insulin $+\log$ fasting glucose).

\section{Biochemical analyses}

Plasma glucose concentrations during the clamp were measured by the glucose oxidase method on an on-site GM9-glucose analyzer (Analox, London, UK). Serum insulin concentrations were measured using an IRMA (Bi-Insulin IRMA, Cis Bio, Bagnols/Cèze, France). Alanine transaminase, aspartate transaminase, $\gamma$-glutamyltransferase, and alkaline phosphatase were determined by enzymatic methods using an ADVIA analyzer (Siemens, Bayer Diagnostics). Triglycerides and total cholesterol were determined according to the standard methods with the use of automated equipment. HbAlc levels were measured by ion exchange HPLC. Serum leptin concentrations were measured $24 \mathrm{~h}$ after the last injection using a specific RIA (Linco Research, St Charles, MO, USA). Sensitivity of the leptin assay is $0.4 \mathrm{ng} / \mathrm{ml}$. Intra- and inter-assay coefficients of variation are 5.2 and $8.7 \%$ respectively at $2.3 \mathrm{ng} / \mathrm{ml}$.

\section{Assessment of leptin antibodies}

Anti-leptin antibodies were measured in serum samples using a sensitive radioassay preceded by dextrancharcoal extraction of serum leptin. Briefly, $200 \mu \mathrm{l}$ of serum were mixed by gentle stirring with $250 \mu \mathrm{l}$ of $0.085 \mathrm{M} \mathrm{HCl}$ and $100 \mu \mathrm{l}$ of dextran-charcoal suspension. After centrifugation, $80 \mu \mathrm{l}$ of supernatant were 
incubated with 20000 c.p.m. of ${ }^{125}$ iodine-labeled leptin (Linco Research), with or without the addition of $2.5 \mathrm{ng}$ of cold human leptin. Polyethylene glycol (1.5 ml, PEG) solution in buffer $(15 \%, \mathrm{v} / \mathrm{v})$ was added to the tubes, which after $20 \mathrm{~min}$ were centrifuged and counted in a gamma counter after aspiration of the supernatant. In control sera, the bound radioactivity (mean \pm s.D.) was $4.8 \pm 0.7 \%$ before the addition of cold leptin, and $4.3 \pm 0.5$ after displacement of bound radioactive leptin by cold leptin (difference $0.53 \pm 0.29 \%$ ). A sample was considered positive for the presence of anti-leptin antibodies when the percent binding was $>6.9 \%$ of total radioactivity (mean of controls +3 s.D.), and the difference between binding before displacement and after displacement was $>1.5 \%$ of total radioactivity (control mean displacement +3 S.D).

\section{Neutralizing antibodies}

Cerebral cortices taken from embryonic mice at 14 days of gestational age were dissected free from the meninges in HEPES-buffered Hank's solution (HBSS, Gibco). Brain tissue was dissociated first enzymatically (0.25\% trypsin in HBSS followed by DNase digestion), and then mechanically (20-30 passages through a Pasteur pipette). Cells were resuspended in Eagle's minimum essential medium (Sigma) containing 10\% horse serum, $2 \mathrm{mM}$ glutamine, and $33 \mathrm{mM}$ glucose, and were plated on 12-mm coverslips coated with poly-DL-ornithine (Sigma). Cultures were kept at $37^{\circ} \mathrm{C}$ in a humidified $\mathrm{CO}_{2}$-containing atmosphere. After 2-4 h, the medium was replaced by Neurobasal medium supplemented with B27 (Life Technologies). On the fifth culture day, one-third of the plating medium was changed, and $5 \mu \mathrm{M}$ cytosine arabinoside was added to halt nonneuronal cell division. Nine- to 11-day-old mature neuronal cultures that displayed extensive axonal networks and were almost devoid of glial cells were exposed for $20 \mathrm{~h}$ to $10 \mathrm{ng} / \mathrm{ml}$ recombinant mouse leptin (R\&D Systems Europe, Lille, France) alone, or in combination with either $100 \mu \mathrm{g} / \mathrm{ml}$ neutralizing antileptin antibody (R\&D Systems) or $10 \mu \mathrm{l} / \mathrm{ml}$ serum from human controls or from patients. $N$-methyl-D-aspartate (NMDA; Tocris Bioscience, Bristol, UK), $300 \mu \mathrm{M}$, or saline was added for $1 \mathrm{~h}$, and it was then replaced by NMDA-free Neurobasal-B27 medium. Eight hours later, the cells were rapidly washed with PBS and fixed with $4 \%$ paraformaldehyde in PBS (PFA, $\mathrm{pH} 7.4$ ) for $1 \mathrm{~h}$. Cell viability was assessed by incubating the cells in $10 \mu \mathrm{g} / \mathrm{ml} \mathrm{Hoechst} \mathrm{dye} \mathrm{(Sigma)} \mathrm{for} 10 \mathrm{~min}$; after two washes in PBS, fluorescence of stained chromatin was examined under a Zeiss microscope equipped with a fluorescent light source. Neurons were evaluated for signs of chromatin condensation indicative of apoptosis. Culture viability was calculated as the ratio of the number of slightly stained cells (viable cells) over the total number of cells counted (viable plus apoptotic cells) expressed as a percentage and normalized for the mean percentage in the control cultures. Cells were counted in 6-10 random fields for each plate. Each experimental group included 3-4 plates. Data were pooled from three or more independent experiments.

\section{Statistical considerations}

All data are given as mean \pm 1 s.D. Variation of the median of the values during the trial was tested using non-parametric two-way repeated-measures analysis of variance by ranks (Friedman test). Change in the mean percentage of pyknotic nuclei was compared using the non-parametric Wilcoxon-Mann-Whitney test. A $P$ value $<0.05$ was considered statistically significant.

\section{Results}

\section{Metabolic response to substitutive therapy}

At enrollment, all patients had nearly no measurable body fat or circulating concentrations of leptin. Despite their restricted diet, six of eight patients demonstrated fasting hypertriglyceridemia (Table 1 and Fig. 1A). Mean ( \pm s.D.) total and high density lipoprotein (HDL) cholesterol were $3.9 \pm 1.8$ and $0.84 \pm 0.16 \mathrm{mmol} / \mathrm{l}$ respectively. All patients had marked to extreme hepatomegaly as measured by CT scan (Fig. 1C). In five of seven patients, the ratio of hepatic to splenic CT attenuation was under 0.95, indicating that fat accumulation was in the liver. Hepatic enzymes were increased in five patients (Table 1). Before therapy, all patients showed elevated fasting insulin (30.6 $\pm 13.4 \mathrm{mUI} / \mathrm{l})$ suggesting a marked degree of insulin resistance, which was confirmed by their very low glucose uptake (between 0.43 and $5.6 \mathrm{mg} / \mathrm{kg}$ per min) at steady state during the euglycemic-hyperinsulinemic clamp (Fig. 1B). Only one patient (patient 5) had overt diabetes with very high HbAlc levels (Table 1).

Changes in triglyceride concentrations, insulin sensitivity, and liver volume are shown in Fig. 1A-C, with response patterns over the whole trial being summarized in Table 2. Characteristics of the patients at 28 months of therapy are given in Table 1 .

During treatment, residual serum leptin concentrations increased, and were sustained within the physiological to supraphysiological ranges (from $1.85 \pm 0.01 \mathrm{ng} / \mathrm{ml}$ at MO to $238.2 \pm 519 \mathrm{ng} / \mathrm{ml}$ at M28, $P=0.008)$. Simultaneously, patients with a total or partial response to treatment showed a transient reduction in appetite, but this effect was attenuated after 6-12 months of therapy and was not associated with either changes in resting respiratory quotient (from $0.78 \pm 0.03$ to $0.8 \pm 0.06$, NS) or changes in resting energy expenditure (from $39.86 \pm 11.56$ to 45.6 $\pm 17.1 \mathrm{kcal} / \mathrm{kg}$ per $\mathrm{mn}$, NS). Leptin neither induced 

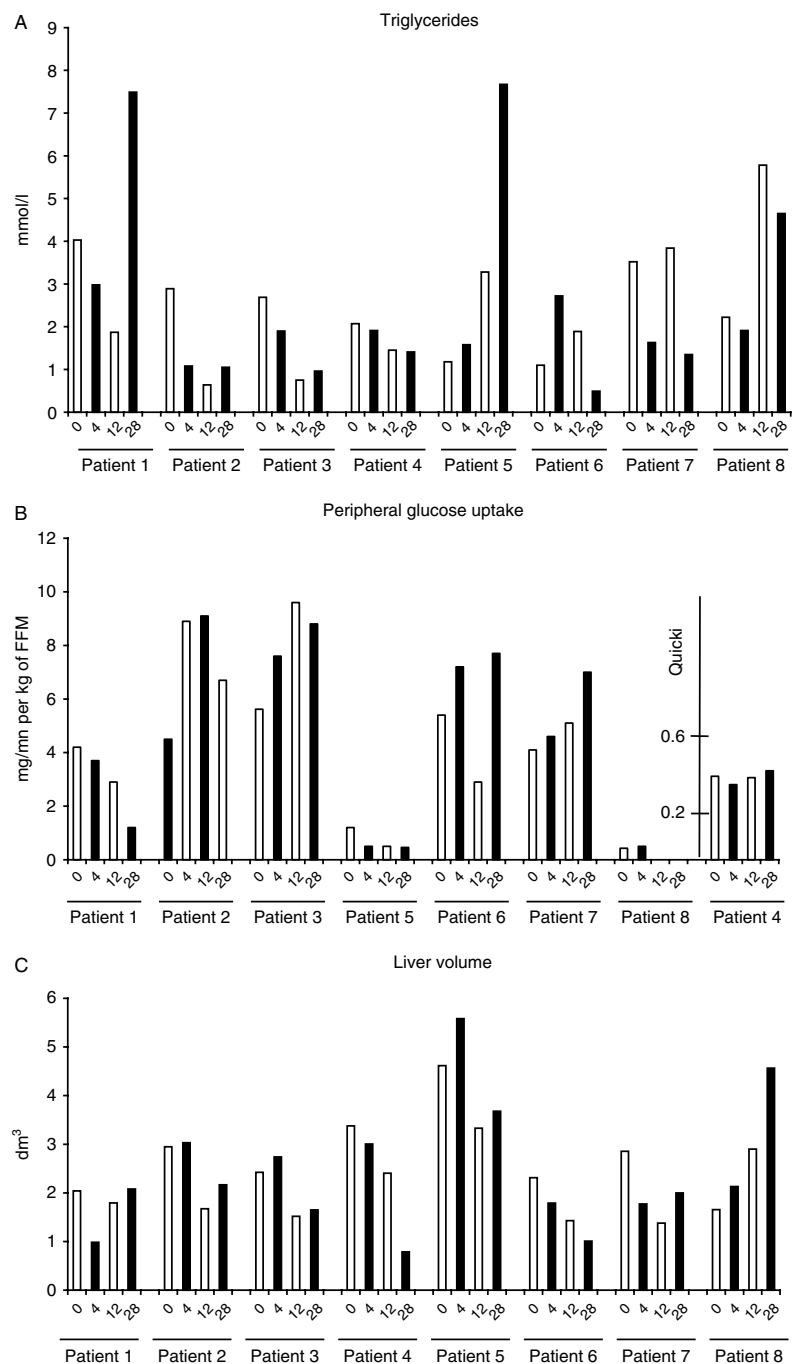

Figure 1 Serum triglyceride concentrations (A), insulin sensitivity (B), and liver volume (C) at months $0,4,12$, and 28 of leptinreplacement treatment in children with $B S C L$.

earlier puberty in the prepubertal children nor corrected amenorrhea of patient 5 nor changed bone density $z$-score (from $2.06 \pm 1.07$ to $2.13 \pm 1.1$ s.D., NS).

Serum triglyceride concentrations returned to physiological values in four patients (patients 2, 3, 6, and 7) within the first 4 months of treatment and in one more patient (patient 4) at the end of the first year (Fig. 1A). Four of these patients maintained normal fasting triglycerides concentrations until month 28 , while dyslipidemia reappeared at the end of the first year in patient 6 and could not be corrected by increasing the dosage. Triglyceride concentrations remained elevated throughout the trial in patients 1,5 , and 8 . HDL cholesterol levels did not change over the course of the 28 months (from $0.84 \pm 0.16$ to $0.85 \pm 0.2 \mathrm{mmol} / \mathrm{l}$, NS) in all patients.

Patients 2, 3, and 7 showed an improvement in insulin sensitivity, the values of which returned to physiological levels (Fig. 1B). Patient 6 only showed a transient improvement during the first 4 months of the trial, while insulin resistance reappeared at the end of the first year and could only be corrected by increasing the dosage. By contrast, there was no improvement in insulin sensitivity in patient 4 . Patients 1,5 , and 8 showed a marked aggravation of insulin resistance. Patient 5 showed a dramatic deterioration in the metabolic control of diabetes with $\mathrm{HbAlc}$ reaching $12.2 \%$ at 28 months. Similarly, patient 8 developed severe clinical diabetes under leptin therapy at the maximal dosage.

Five patients demonstrated an improvement in liver volume (patients 2, 3, 4, 6, and 7; Fig. 1C) with a decrease in the ratio of hepatic to splenic CT scan attenuation $(>00.95)$ indicating reduction of hepatic steatosis.

Altogether, after 28 months of therapy, a total response was observed in only three patients, with the leptin dose being increased up to $0.09 \mathrm{mg} / \mathrm{kg}$ per day in two of these patients (Table 2). Two other patients demonstrated a partial response with the same dosage. The remaining three patients demonstrated a negative response at 28 months of therapy with the maximal dosage of leptin, whereas glycemic control was not improved in the two diabetic patients.

\section{Assessment and characterization of antibodies against recombinant leptin}

In an attempt to explain the total or partial resistance to the metabolic effects of leptin, we postulated the formation of anti-leptin antibodies triggered by the administration of the peptidic hormone. An in-house assay was developed to specifically detect these antibodies. At the beginning of the second trial, leptin binding to molecules precipitated by PEG was detectable in the seven patients who had previously been enrolled in the first 4-month trial, and which was followed by a washout period of 18 months. This percentage of binding was lowest in the patients who were later total responders $(7.6,10.1$, and $9.1 \%$ respectively in patients 2,3 , and 7), and by contrast, the highest (29.9 and $17 \%$ ) occurred in non-responding patients.

After 28 months in the second trial, binding increased in all patients, but it increased more dramatically in patients with a negative response than in patients with a total response (Fig. 2). The molecular weight of the binding molecules as assessed by gel filtration was found to be close to $150 \mathrm{kDa}$, a value consistent with that of a leptin-antibody complex.

In order to further investigate the neutralizing effect of these antibodies, we used an in vitro assay that was previously used to demonstrate the neuroprotective effect of leptin to NMDA exposure in embryonic neurons in primary culture. Even if looking at the neuroprotective effects may not be relevant with respect to the metabolic effects of leptin, the former involves part of the 

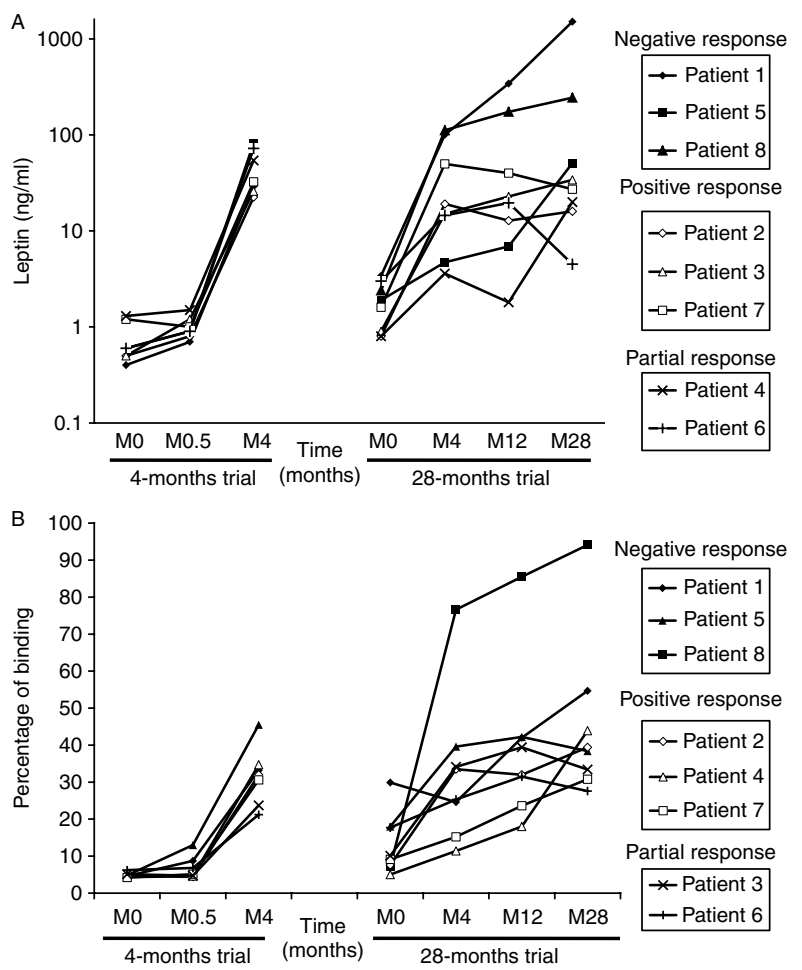

Figure 2 Changes in residual serum leptin concentrations $(A)$ and in antibodies (B) during the first 4-month trial (retrospective analysis) and during the second 28-month trial. Panel A, logarithmic scale;

Panel B, percent of fixation against leptin - regular scale.

classical intracellular signaling pathway in the response of leptin binding to its receptor and could then be used to demonstrate the neutralizing effect of antibodies on the leptin signaling pathway. In the NMDA-treated culture, cell death reached $40 \%$, but was decreased to $20 \%$ when the culture was co-treated with leptin (Fig. 3). The addition of a commercial neutralizing

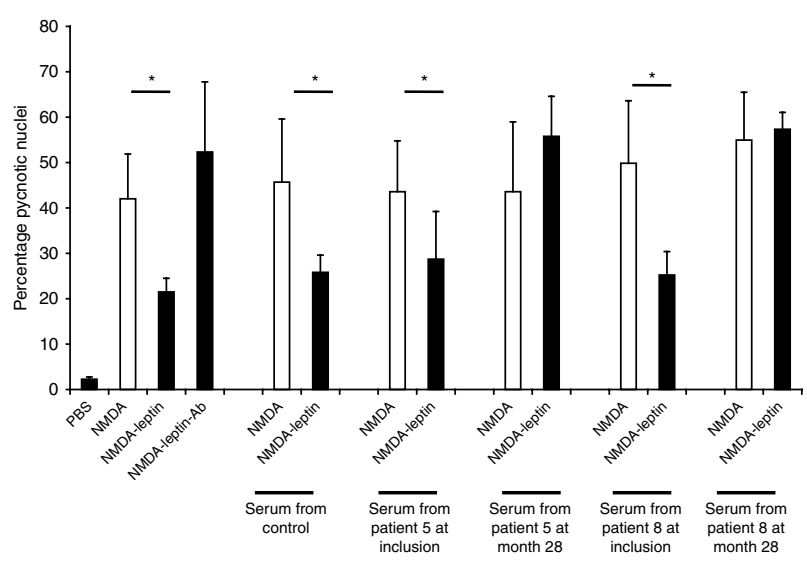

Figure 3 In vitro neutralizing effect of patients' antibodies. Percentage of pyknotic cells in primary neuron cell culture. Cells were co-incubated with NMDA (concentration) and serum from control or from patient 5 or 6 (serum from inclusion or from month 28) with or without leptin. ${ }^{*} P<0.05$ (Wilcoxon-Mann-Whitney test). antibody led to a similar number of apoptotic cells that reported with NMDA culture alone (Fig. 3). At the commencement of the second trial, NMDA-treated cells were co-incubated in the presence of serum from two patients who later showed a negative response (serum from patient 5: binding $=18 \%$ and serum from patient 8 : binding $=7.2 \%$ ) with or without leptin. As shown in Fig. 3, leptin still induced a decrease in the number of apoptotic cells. By contrast, addition of serum from the same patients at month 28 of therapy ( $45 \%$ of binding in patient 5 and $94 \%$ of binding in patient 8 ) inhibited the neuroprotective effect of leptin, demonstrating the neutralizing effect of antibodies in this situation. Furthermore, the residual leptin concentrations were low in patients with a total response despite the presence of antibodies. The higher residual concentrations in patients with a negative response were associated with higher binding, suggestive of a trapping effect of leptin.

\section{Discussion}

In this 28-month trial of children with BSCL, the majority of the patients developed a partial or total resistance to the metabolic effects of the recombinant leptin despite a significant progressive increase in the leptin dosage. The need for an increasing dosage to maintain the metabolic effects of leptin has been reported in other trials, such as those in children with congenital leptin deficiency (18-20). However, in the present trial, even the high doses of leptin failed to improve glycemic control or antidiabetic agent dosage requirements in the two diabetic patients, which is in clear contrast to the results from previous trials reported in the literature $(13,14)$. This pattern of 'resistance' to a peptidic hormone prompted us to postulate a possible immune mechanism responsible for such 'leptin resistance'. The occurrence of antibodies in patients undergoing leptin-substitutive treatment has been reported in children with congenital leptin (19) deficiency, but it is poorly documented in BSCL. Antibodies were not mentioned in the American trial conducted in lipodystrophic adults (13), and antibodies reported in Japanese patients were not characterized as neutralizing (14). We demonstrated, in vitro, a neutralizing effect of the sera of two patients on the neuroprotective effect of leptin in primary culture of embryonic neurons (21). Upon retrospective analysis, we found that these antibodies appeared early, during the first 4-month trial after the end of the first month of leptin administration, and further increased thereafter.

The appearance of antibodies following a substitutive hormonal therapy has been reported with other recombinant proteins (22-27), and it can suggest some mechanisms for the resistance reported here. In type 1 diabetic patients, the production of antibodies against insulin is common but without reported clinical 
relevance, and has been observed with bovine, porcine, and recombinant insulin (25-27). Antibody production interfering with the treatment effect has been well documented in children with congenital GH deficiency (22-24). In some cases, this resistance seemed to be linked to the change in the amino acid sequence of the recombinant protein (28).

As reported in animal models of congenital leptin deficiency, the transient beneficial effects that we reported previously in these patients could be linked to transitory effects on satiety regulation leading to a decrease in nutritional intake and then to circulating lipids (29). In humans, some data are available on the effects of leptin-substitutive therapy on neuronal activation in key striatal regions in patients with congenital leptin deficiency; these data suggest that the recombinant hormone acts on neural circuits governing food intake to diminish the perception of food reward while enhancing the response to satiety signals generated during food consumption (30). Such effects would appear rapidly (in the first 2 weeks) after the beginning of leptin therapy (30). Here, we have demonstrated in vitro that antibodies produced by some patients canceled out the biological effect of leptin on embryonic neurons. If the biological effect investigated in vitro is not the one of appetite control, we can suggest that the lack of clinical effect that we reported in this second trial could be at least partly linked to a lack of central effects of the therapy. We did not record calorie intake, but parents constantly reported increased satiety over the first few months of therapy. This effect rapidly disappeared in patients with a negative response and was attenuated after some months of therapy in other patients, only re-appearing in the weeks following the increase in dosage. However, we did not observe changes in resting energy expenditure, which is not in keeping with an effect on neuronal pathways controlling energy expenditure. Interestingly, the only effect that was maintained over time in our patients - but at the price of increasing the dosage of leptin - was the reduction of hepatic steatosis, arguing for an additional peripheral effect of the molecule (31).

Therefore, we report here that some lipodystrophic patients developed a resistance to leptin-substitutive therapy blunting the beneficial effects we reported previously. This resistance could be mediated, at least in some patients, through an immunological process with severe clinical consequences since therapeutic alternatives in these patients are poor and ineffective in inhibiting the life-threatening prognosis of the disease.

\section{Declaration of interest}

J Beltrand, N Lahlou, T Le Charpentier, G Sebag, S Leka, M Polak, N Tubiana-Rufi, D Lacombe, M de Kerdanet, F Huet, J-J Robert, D Chevenne, and P Gressens have nothing to declare. C Lévy-Marchal received lecture fees from Pfizer Inc., NovoNordisk Inc., and Lilly Inc.

\section{Funding}

This work was supported by a grant from the COSSEC/Institut National de la Santé et de la Recherche Médicale (INSERM). J Beltrand was supported by a grant from INSERM (Poste d'accueil, 2007). N Lahlou was partly supported by a grant from Institut de Recherche Endocrinienne et Métabolique (Paris, France). The funders had no role in the study design, data collection and analysis, decision to publish, or preparation of the manuscript.

\section{Acknowledgements}

The authors are grateful to the nursing staff of the Clinical Investigation Centre (CIC-9202) of Robert Debré Hospital and Miss Lila Benadjaoud. They acknowledge the skillful technical assistance of Mr François Luc (CIC-9202) and Ms Leslie Schwendimann (INSERM U676).

\section{References}

1 Berardinelli W. An undiagnosed endocrinometabolic syndrome: report of 2 cases. Journal of Clinical Endocrinology and Metabolism 195414 193-204.

2 Seip M \& Trygstad O. Generalized lipodystrophy. Archives of Disease in Childhood 196338 447-453.

3 Agarwal AK, Arioglu E, De Almeida S, Akkoc N, Taylor SI, Bowcock AM, Barnes RI \& Garg A. AGPAT2 is mutated in congenital generalized lipodystrophy linked to chromosome 9q34. Nature Genetics 200231 21-23.

4 Magré J, Delepine M, Khallouf E, Gedde-Dahl TJ, Van Maldergem L, Sobel E, Papp J, Meier M, Mégarbané A, Group BW, Lathrop M \& Capeau J. Identification of the gene altered in Berardinelli-Seip congenital lipodystrophy on chromosome 11q13. Nature Genetics 200128 365-370.

5 Kim CA, Delepine M, Boutet E, El Mourabit H, Le Lay S, Meier M, Nemani M, Bridel E, Leite CC, Bertola DR, Semple RK, O'Rahilly S, Dugail I, Capeau J, Lathrop M \& Magre J. Association of a homozygous nonsense caveolin-1 mutation with Berardinelli-Seip congenital lipodystrophy. Journal of Clinical Endocrinology and Metabolism 200893 1129-1134.

6 Szymanski KM, Binns D, Bartz R, Grishin NV, Li WP, Agarwal AK, Garg A, Anderson RG \& Goodman JM. The lipodystrophy protein seipin is found at endoplasmic reticulum lipid droplet junctions and is important for droplet morphology. PNAS 2007 104 20890-20895.

7 Capeau J, Vigouroux C, Magre J, Lascols O, Caron M \& Bastard JP. Lipodystrophic syndromes: congenital or acquired diseases of adipose tissue. Comptes Rendus Biologies 2006329 639-652 discussion 653-5.

8 Jaquet D, Khallouf E, Levy_Marchal C \& Czernichow P. Extremely low values of serum leptin in children with congenital generalized lipoatrophy. European Journal of Endocrinology $1999 \mathbf{1 4 0}$ 107-109.

9 Gavrilova O, Marcus-Samuels B, Leon LR, Vinson C \& Reitman ML. Leptin and diabetes in lipoatrophic mice. Nature 2000403850 discussion 850-851.

10 Minokoshi Y, Kim YB, Peroni OD, Fryer LG, Muller C, Carling D \& Kahn BB. Leptin stimulates fatty-acid oxidation by activating AMP-activated protein kinase. Nature 2002415 339-343.

11 Shimomura I, Hammer RE, Ikemoto S, Brown MS \& Goldstein JL. Leptin reverses insulin resistance and diabetes mellitus in mice with congenital lipodystrophy. Nature 1999 401 73-76.

12 Unger RH, Zhou Y-T \& Orci L. Regulation of fatty acid homeostasis in cells: novel role of leptin. PNAS 199996 2327-2332.

13 Javor ED, Cochran EK, Musso C, Young JR, DePaoli AM \& Gorden P. Long-term efficacy of leptin replacement in patients with generalized lipodystrophy. Diabetes 200554 1994-2002. 
14 Ebihara K, Kusakabe T, Hirata M, Masuzaki H, Miyanaga F, Kobayashi N, Tanaka T, Chusho H, Miyazawa T, Hayashi T, Hosoda K, Ogawa Y, DePaoli AM, Fukushima M \& Nakao K. Efficacy and safety of leptin-replacement therapy and possible mechanisms of leptin actions in patients with generalized lipodystrophy. Journal of Clinical Endocrinology and Metabolism $200792532-541$.

15 Beltrand J, Beregszaszi M, Chevenne D, Sebag G, De Kerdanet M, Huet F, Polak M, Tubiana-Rufi N, Lacombe D, De Paoli AM \& LevyMarchal C. Metabolic correction induced by leptin replacement treatment in young children with Berardinelli-Seip congenital lipoatrophy. Pediatrics 2007120 e291-e296.

16 Livesey G \& Elia M. Estimation of energy expenditure, net carbohydrate utilization, and net fat oxidation and synthesis by indirect calorimetry: evaluation of errors with special reference to the detailed composition of fuels. American Journal of Clinical Nutrition $1988 \mathbf{4 7} 608-628$.

17 DeFronzo RA, Tobin JD \& Andres R. Glucose clamp technique: a method for quantifying insulin secretion and resistance. American Journal of Physiology 1979237 E214-E223.

18 Farooqi IS, Jebb SA, Langmack G, Lawrence E, Cheetham $\mathrm{CH}$, Prentice AM, Hughes IA, McCamish MA \& O'Rahilly S. Effects of recombinant leptin therapy in a child with congenital leptin deficiency. New England Journal of Medicine 1999341 879-884.

19 Farooqi IS, Matarese G, Lord GM, Keogh JM, Lawrence E, Agwu C, Sanna V, Jebb SA, Perna F, Fontana S, Lechler RI, DePaoli AM \& O'Rahilly S. Beneficial effects of leptin on obesity, T cell hyporesponsiveness, and neuroendocrine/metabolic dysfunction of human congenital leptin deficiency. Journal of Clinical Investigation $20021101093-1103$.

20 Gibson WT, Farooqi IS, Moreau M, DePaoli AM, Lawrence E, O'Rahilly S \& Trussell RA. Congenital leptin deficiency due to homozygosity for the $\Delta 133 \mathrm{G}$ mutation: report of another case and evaluation of response to four years of leptin therapy. Journal of Clinical Endocrinology and Metabolism $2004894821-4826$.

21 Dicou E, Attoub S \& Gressens P. Neuroprotective effects of leptin in vivo and in vitro. Neuroreport 200112 3947-3951.

22 Ahangari G, Ostadali MR, Rabani A, Rashidian J, Sanati MH \& Zarindast MR. Growth hormone antibodies formation in patients treated with recombinant human growth hormone. International Journal of Immunopathology and Pharmacology 200417 33-38.
23 Massa G, Vanderschueren-Lodeweyckx M \& Bouillon R. Five-year follow-up of growth hormone antibodies in growth hormone deficient children treated with recombinant human growth hormone. Clinical Endocrinology 199338 137-142.

24 Rougeot C, Marchand P, Dray F, Girard F, Job JC, Pierson M, Ponte C, Rochiccioli P \& Rappaport R. Comparative study of biosynthetic human growth hormone immunogenicity in growth hormone deficient children. Hormone Research 199135 76-81.

25 Fireman P, Fineberg SE \& Galloway JA. Development of IgE antibodies to human (recombinant DNA), porcine, and bovine insulins in diabetic subjects. Diabetes Care 1982 5 119-125.

26 Himanshu M, Bhat CB, Ramchandran S, Bhat KG \& Kumar PK. Immunogenicity of human and bovine insulin in type 1 diabetes mellitus patients. Diabetes Technology and Therapeutics 200810 305-309.

27 Schernthaner G. Immunogenicity and allergenic potential of animal and human insulins. Diabetes Care 199316 155-165.

28 Pitukcheewanont P, Schwarzbach L \& Kaufman FR. Resumption of growth after methionyl-free human growth hormone therapy in a patient with neutralizing antibodies to methionyl human growth hormone. Journal of Pediatric Endocrinology \& Metabolism 200215 653-657.

29 Prieur X, Tung YC, Griffin JL, Farooqi IS, O'Rahilly S \& Coll AP. Leptin regulates peripheral lipid metabolism primarily through central effects on food intake. Endocrinology 2008149 5432-5439.

30 Farooqi IS, Bullmore E, Keogh J, Gillard J, O’Rahilly S \& Fletcher PC. Leptin regulates striatal regions and human eating behavior. Science $2007 \mathbf{3 1 7} 1355$.

31 Mulligan K, Khatami H, Schwarz JM, Sakkas GK, DePaoli AM, Tai VW, Wen MJ, Lee GA, Grunfeld C \& Schambelan M. The effects of recombinant human leptin on visceral fat, dyslipidemia, and insulin resistance in patients with human immunodeficiency virus-associated lipoatrophy and hypoleptinemia. Journal of Clinical Endocrinology and Metabolism 200994 1137-1144.

Received 2 March 2010

Accepted 16 March 2010 